\title{
Copper- and zinc-containing superoxide dismutase (Cu/ZnSOD) is required for the protection of Candida albicans against oxidative stresses and the expression of its full virulence
}

\author{
Cheol-Sang Hwang, Gi-eun Rhie, Jang-Hyun Oh, Won-Ki Huh, \\ Hyung-Soon Yim and Sa-Ouk Kang
}

Laboratory of Biophysics, School of Biological Sciences and Institute of Microbiology,

Seoul National University, Seoul 151-742,

Republic of Korea

\author{
Author for correspondence: Sa-Ouk Kang. Tel: +82 2880 6703. Fax: +82 28884911. \\ e-mail:kangsaou@plaza.snu.ac.kr
}

\begin{abstract}
Copper- and zinc-containing superoxide dismutase (Cu/ZnSOD) is suspected to be one of the anti-oxidant enzymes and virulence determinants active in some pathogenic micro-organisms. To elucidate the role of Cu/ZnSOD in the major human fungal pathogen Candida albicans, its gene, designated SOD1, was disrupted by the URA-blaster technique. The resulting sod1/sod1 mutant showed delayed hyphal growth on Spider medium but could still form hyphae on other solid media or in liquid media, particularly in response to serum. Moreover, the sod1/sod1 mutant was more sensitive to menadione, a redoxcycling agent, than the isogenic wild-type strain, although it still showed an adaptive oxidative stress response. Furthermore, the sod1/sod1 mutant cells exhibited slow growth in minimal medium when compared to the wild-type cells, but their growth was restored by the addition of lysine to the medium. Interestingly, C. albicans cells lacking Cu/ZnSOD showed increased susceptibility to macrophage attack and had attenuated virulence in mice. Thus, these results suggest that Cu/ZnSOD is required for the protection of $C$. albicans against oxidative stresses and for the full virulence of the organism to be expressed.
\end{abstract}

Keywords: SOD1, hyphal growth, lysine auxotrophy, candidiasis

\section{INTRODUCTION}

Although aerobic organisms obtain many benefits from dioxygen in their respiration and other functions, they often encounter highly toxic reactive oxygen species (ROS) such as superoxide radical anions, hydrogen peroxide and hydroxyl radicals. These ROS are a result of incomplete oxidation during aerobic metabolism. Therefore, many organisms have evolved that have antioxidants and anti-oxidant enzymes to protect themselves from highly toxic ROS (Fridovich, 1989, 1995).

Superoxide dismutase (SOD), an anti-oxidant enzyme, catalyses the dismutation of superoxide radical anions

Abbreviations: $\mathrm{Cu} / \mathrm{ZnSOD}$, copper- and zinc-containing SOD; FeSOD, iron-containing SOD; MnSOD, manganese-containing SOD; ROS, reactive oxygen species; SG, synthetic glucose; SGU, SG plus $25 \mu \mathrm{g}$ uridine $\mathrm{ml}^{-1}$; SOD, superoxide dismutase. to dioxygen and hydrogen peroxide. Generally, SODs are categorized into four classes according to their metal cofactors - copper- and zinc-containing SOD $(\mathrm{Cu} /$ $\mathrm{ZnSOD})$, manganese-containing SOD (MnSOD), ironcontaining SOD (FeSOD) and nickel-containing SOD (Fridovich, 1989, 1995; Youn et al., 1996a, b). Cu/ ZnSOD is found mostly in the cytosol (Fridovich, 1989, 1995 ) and mitochondria of eukaryotic cells (OkadoMatsumoto \& Fridovich, 2001) and in the periplasmic space of some prokaryotes (Battistoni et al., 1998; Farrant et al., 1997; Wilks et al., 1998). This enzyme has been shown to play a role in protecting cells against oxygen toxicity (Fridovich, 1989, 1995) and to act as a major repository for copper ions in virtually all eukaryotes (Culotta et al., 1995); however, the loss of $\mathrm{Cu} / \mathrm{ZnSOD}$ activity has various pleiotropic consequences on organisms, which include slow growth, conditional auxotrophies and DNA damage (Fridovich, 
1989, 1995). For example, a Cu/ZnSOD-null yeast strain was shown to be oxygen-sensitive, hypermutable, auxotrophic for lysine and methionine and defective in sporulation (Liu et al., 1992). In some pathogenic organisms, $\mathrm{Cu} / \mathrm{ZnSOD}$ has also been proposed as being a virulence determinant that could decompose the superoxide radical anions generated by phagocytic cells (Hong et al., 1992; Farrant et al., 1997; Wilks et al., 1998; Battistoni et al., 1998).

Candida albicans, the major fungal pathogen of humans, causes not only oral and vaginal thrush but also systemic or life-threatening infections in immunocompromised patients (Cutler, 1991; Coleman et al., 1993). A number of factors are known to be involved in the virulence of $C$. albicans, such as its adhesion to host tissues, its evasion of the host immune system, its secretion of protease and its reversible morphological conversion from yeast to hyphal growth (Cutler, 1991; Vázquez-Torres \& Balish, 1997). Once C. albicans has infected a host, it inevitably encounters ROS produced by host phagocytes as well as ROS produced as a consequence of its own oxygen metabolism. Since phagocytic cells produce the superoxide radical anion, the first intermediate in the sequential univalent reduction of dioxygen, during the oxidative burst, the SODs of C. albicans are thought to play a protective role in this organism by suppressing oxidative killing by the infected host (Vázquez-Torres \& Balish, 1997).

Although SODs are important anti-oxidant enzymes and have an additional hypothetical role in the virulence of pathogenic fungi (Hamilton \& Holdman, 1999), there is no direct evidence that SODs are involved in the pathogenicity of C. albicans. We have previously reported the characterization of $\mathrm{Cu} / \mathrm{ZnSOD}$ and its gene from C. albicans (Hwang et al., 1999). The present study shows that $\mathrm{Cu} / \mathrm{ZnSOD}$ of $\mathrm{C}$. albicans contributes to the protection of this organism against oxidative stresses and to the establishment of the full virulence of this organism. This is the first report to provide direct evidence that $\mathrm{Cu} / \mathrm{ZnSOD}$ is involved in the virulence of pathogenic fungi.

\section{METHODS}

Organisms and culture conditions. C. albicans strains and plasmids used in this study are listed in Table 1 . The strains were routinely cultured on YPG ( $1 \%$ yeast extract, $2 \%$ peptone, $2 \%$ glucose) medium at $28{ }^{\circ} \mathrm{C}$. Cells carrying plasmids or disrupted genes were cultured in synthetic glucose (SG) medium containing $0.67 \%$ yeast/nitrogen base without amino acids (Difco), $2 \%$ glucose and appropriate supplements. Amino-acid requirements of the strains for growth were tested by seeding cells to an $\mathrm{OD}_{600}$ value of 0.01 in SG medium supplemented with various amino acids as needed. Solid media were prepared by adding $1.4 \%$ agar to liquid broth. Escherichia coli DH5 $\alpha$ was used for most plasmid construction and maintenance, and cells of this strain were grown at $37^{\circ} \mathrm{C}$ in Luria-Bertani medium supplemented with appropriate antibiotics.

DNA manipulation and analysis. Plasmid isolation, PCR, restriction-enzyme digestion, cloning and Southern blot hybridization were carried out by standard methods (Sambrook et al., 1989). Labelling of the DNA probes was performed by using the non-radioactive labelling and detection kit (Roche Molecular Biochemicals). The coding region of SOD1 in pCH101 was labelled by random-primed incorporation of digoxigenin-tagged dUTP.

Disruption and re-integration of C. albicans SOD1. To disrupt both alleles of SOD1 using the URA-blaster technique (Fonzi \& Irwin, 1993), the oligonucleotide primers 5'-GTTCATTTTGAACAAGAA-3' and 5'-GCCAATGACACCACAAGC$3^{\prime}$ were used. The resulting 402 bp PCR product was inserted into the pGEM-T Easy vector (Promega), yielding pCH101. A $4 \cdot 1 \mathrm{~kb}$ his $G-U R A 3-$ his $G$ cassette from p5921 (Fonzi \& Irwin, 1993) was then inserted into a portion of SOD1 within pCH101. The resulting plasmid, pCH102, was cut with ApaI/SacI, to remove the vector, and the disrupted SOD1 gene was transformed into the Ura ${ }^{-}$C. albicans strain CAI4 (Fonzi \& Irwin, 1993). Ura ${ }^{+}$transformants were selected on an uracildeficient medium and the integration of the his $G-U R A 3-$ his $G$ cassette into the SOD1 locus was verified by Southern blot analysis. Spontaneous $\mathrm{Ura}^{-}$derivatives of the heterozygous disruptants were selected on SG medium containing $625 \mu \mathrm{g} \mathrm{5-}$ fluoroorotic acid $\mathrm{ml}^{-1}$ and $100 \mu \mathrm{g}$ uridine $\mathrm{ml}^{-1}$. This procedure was repeated to delete the remaining functional allele of SOD1.

For re-integration of SOD1 into the genome of C. albicans, an $\mathrm{XbaI} / S_{c a l}$-digested URA3 fragment from pURA3 (Huh et al., 2001) was inserted into the $X b a \mathrm{I} / E c o R V$ sites of pSOD1, which was constructed through the ligation of a $2.8 \mathrm{~kb} E c o$ RIdigested genomic DNA fragment containing the SOD1 coding region into pBluescript $\mathrm{KS}(+)$ (Stratagene). The resulting plasmid, pCH103, was linearized by digestion at the unique HpaI site upstream of the coding region of SOD1; the linearized plasmid was integrated into the SOD1 locus of the $\mathrm{Ura}^{-}$strain $\operatorname{sod} 1 / \operatorname{sod} 1$. The targeted re-integration of SOD1 into the genome of sod1/sod1 was confirmed by PCR (data not shown) and Southern blot analysis.

Staining to detect SOD activity. SOD activity on a nondenaturing polyacrylamide gel was detected by negative staining (Manchenko, 1994). The gel was incubated in $50 \mathrm{mM}$ phosphate buffer $(\mathrm{pH} \mathrm{7 \cdot 8)}$ for $10 \mathrm{~min}$, in nitro blue tetrazolium solution $\left(1 \mathrm{mg} \mathrm{ml}^{-1}\right)$ for $10 \mathrm{~min}$ and then in $50 \mathrm{mM}$ phosphate buffer $\left(\mathrm{pH} 7 \cdot 8\right.$ ) containing $0 \cdot 01 \mathrm{mg}$ riboflavin $\mathrm{ml}^{-1}$ and $3.25 \mathrm{mg}$ $N, N, N^{\prime}, N^{\prime}$-tetramethylethylenediamine $\mathrm{ml}^{-1}$ for $10 \mathrm{~min}$ at room temperature with gentle shaking. Areas of SOD activity remained clear when the gel was exposed to the light.

Western blot analysis. The purified $\mathrm{Cu} / \mathrm{ZnSOD}$ enzyme (Hwang et al., 1999) was isolated from a $12 \%$ SDSpolyacrylamide gel and then injected into a mouse (4-week-old ICR female). Boosting with purified $\mathrm{Cu} / \mathrm{ZnSOD}$ was done twice, with a 2 -week interval between each boost; the mouse was killed 10 days after the second boost. A total of $50 \mu \mathrm{g}$ of cell-free extract of C. albicans was subjected to $12 \%$ SDSPAGE. The protein was then transferred onto a nitrocellulose filter and electroblotting was done according to Bollag \& Edelstein (1991). The signals were visualized by using a colorimetric detection kit (Roche Molecular Biochemicals), according to manufacturer's instructions.

Determination of growth rate. To assess the yeast-phase growth rates, an overnight-grown culture of C. albicans was subcultured into YPG or SG media and incubated at $28^{\circ} \mathrm{C}$. The cell density $\left(\mathrm{OD}_{600}\right)$ of these cultures was measured after $4 \mathrm{~h}$ and then every $2 \mathrm{~h}$ up to the stationary phase. The 
Table 1. Strains and plasmids used in this study

\begin{tabular}{|c|c|c|}
\hline Strain/plasmid & Genotype and description & Source/reference \\
\hline \multicolumn{3}{|l|}{ C. albicans } \\
\hline SC5314 & Wild-type isolate & Fonzi \& Irwin (1993) \\
\hline CAI4 & $\Delta u r a 3:: i m m 434 / \Delta u r a 3:: i m m 434$ & Fonzi \& Irwin (1993) \\
\hline CH101 & 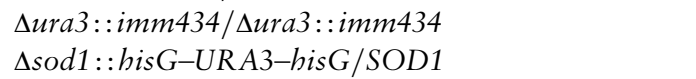 & This work \\
\hline CH102 & 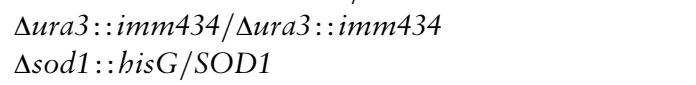 & This work \\
\hline CH103 & 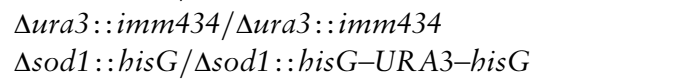 & This work \\
\hline $\mathrm{CH} 104$ & $\begin{array}{l}\text { sura3::imm } 434 / \Delta u r a 3:: i m m 434 \\
\Delta s o d 1:: \text { his } G / \Delta \text { sod } 1:: \text { his } G\end{array}$ & This work \\
\hline CH104R & $\Delta \operatorname{sod} 1::$ his $G / \Delta \operatorname{sod} 1:$ :his $G::$ SOD1::URA3 & This work \\
\hline \multicolumn{3}{|l|}{ Plasmid } \\
\hline p5921 & hisG-URA3-hisG in pUC18 & Fonzi \& Irwin (1993) \\
\hline pURA3 & $U R A 3$ in pGEM-T Easy & Huh et al. (2001) \\
\hline pSOD1 & $\begin{array}{l}2 \cdot 8 \mathrm{~kb} \text { EcoRI-digested genomic SOD1 in pBluescript } \\
\mathrm{KS}(+)\end{array}$ & This work \\
\hline pCH101 & $0.4 \mathrm{~kb}$ PCR fragment of SOD1 in pGEM-T Easy & This work \\
\hline pCH102 & sod1::hisG-URA3-hisG in pGEM-T Easy & This work \\
\hline pCH103 & $U R A 3$ in $\mathrm{pSOD} 1$ & This work \\
\hline
\end{tabular}

doubling time of the cultures during the exponential phase was determined by using the formula $\ln 2 \times t /(\ln b-\ln a)$, where $t$ is the time period in hours, $a$ is the cell density at the beginning of the time period and $b$ is the cell density at the end of the time period. To determine the extension rate of the hyphae, C. albicans cells were incubated in YPG containing $10 \%$ fetal bovine serum (FBS; Gibco-BRL) at $37^{\circ} \mathrm{C}$ and the relative sizes of the $C$. albicans hyphae were measured every $1 \mathrm{~h}$ over a period of $4 \mathrm{~h}$ under a microscope.

Assay for the resistance of $C$. albicans to oxidative stresses. All experiments were done according to the method of Izawa et al. (1995) with some modifications. Cells were grown to mid-exponential phase $\left(2 \times 10^{7}\right.$ cells $\left.\mathrm{ml}^{-1}\right)$, harvested and resuspended in $50 \mathrm{mM}$ potassium phosphate buffer $(\mathrm{pH} 7 \cdot 8)$, to obtain an initial $\mathrm{OD}_{600}$ value of $0 \cdot 1$. To observe the sensitivity of the C. albicans cells to oxidants, various concentrations of menadione or hydrogen peroxide were added to the cell suspensions. After $1 \mathrm{~h}$ incubation at $28{ }^{\circ} \mathrm{C}$, aliquots were taken from the cell suspensions, diluted appropriately in $50 \mathrm{mM}$ potassium phosphate buffer $(\mathrm{pH} \mathrm{7 \cdot 8)}$ and plated onto solid YPG medium. After 2 days incubation at $28^{\circ} \mathrm{C}$, the number of colonies on the plates was counted.

Survival assay in macrophages. To determine the survival rate of C. albicans cells exposed to macrophages (cell-line RAW264.7), we used an end-point dilution survival assay (Rocha et al., 2001). An aliquot (1 ml) of an overnight-grown culture of C. albicans cells was washed twice in PBS and resuspended at $1 \times 10^{7} \mathrm{cells} \mathrm{ml}^{-1}$ in cold $10 \%$ heat-inactivated FBS. An aliquot of the suspension $(50 \mu \mathrm{l})$ was added to $150 \mu \mathrm{l}$ cold $10 \%$ heat-inactivated FBS in 96 -well plates containing medium or only macrophages $\left(1 \times 10^{5}\right.$ cells per well $)$. After four-fold serial dilutions, the plates were incubated on ice for $30 \mathrm{~min}$ and subsequently for $24 \mathrm{~h}$ at $37^{\circ} \mathrm{C}$ in $5 \% \mathrm{CO}_{2}$. Colonies were visualized with the use of an inverted-phase microscope (Zeiss Axiovert 100) at $40 \times$ magnification. Survival of C. albicans was expressed as a percentage of the number of colonies in the presence of macrophages divided by the number of colonies in the absence of macrophages. Data shown represent the mean $\pm \mathrm{SE}$ of three independent experiments.

Virulence studies. Inbred BALB/c mice (Seoul National University Laboratory Animal Center) weighing between 17 and $20 \mathrm{~g}$ were used to test the virulence of the different strains of C. albicans. Two experiments were initiated by growing the C. albicans strains on YPG plates for $48 \mathrm{~h}$ at $28^{\circ} \mathrm{C}$, suspending the cells in PBS and adjusting the suspensions to the desired cell density $\left(\mathrm{OD}_{600}=0 \cdot 5\right)$. The virulence of each $C$. albicans strain (i.e. SC5314, CH103 or CH104R) was tested by injecting $0 \cdot 1 \mathrm{ml}$ of the appropriate cell suspension $\left(1 \times 10^{6}\right.$ cells $)$ into five mice. The statistical analyses of the differences in survival between the paired groups were performed with the KaplanMeier log-rank test. A $P$ value of 0.05 was taken to indicate statistical significance in the results.

\section{RESULTS}

\section{Disruption of SOD1 in C. albicans}

We have previously reported the characterization of $\mathrm{Cu} / \mathrm{ZnSOD}$ and its gene from C. albicans (Hwang et al., 1999). To determine its role in C. albicans, SOD1 (GenBank accession no. AF046872) was sequentially disrupted by using the URA-blaster technique (Fig. 1a). Homozygous disruption of the SOD1 gene was confirmed by PCR (data not shown) and Southern blot analysis (Fig. 1b). Our previous studies have shown that purified $\mathrm{Cu} / \mathrm{ZnSOD}$ is $19.6 \mathrm{kDa}$ in size after SDS-PAGE and that its activity appears in the lower of the two SOD bands detected after activity staining (Hwang et al., 1999; Rhie et al., 1999). Thus, the loss of $\mathrm{Cu} / \mathrm{ZnSOD}$ can be confirmed by Western blot analysis (Fig. 2a) and 


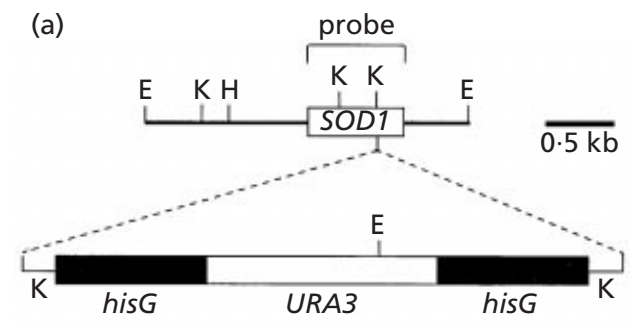

(b)

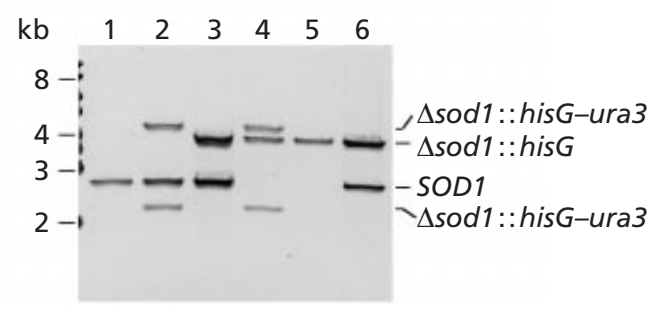

Fig. 1. Disruption of SOD1 in C. albicans. (a) Schematic representation of the disruption strategy used. The restriction map of the SOD1 locus and insertion of the hisG-URA3-hisG cassette at the indicated $K p n I$ site in the SOD1-coding sequence are shown. E, EcoRI; K, Kpnl; H, Hpal. (b) Southern blot analysis with the sequences bracketed in (a) used as probes (shown at right of image). The DNA digested with EcoRI was from CAI4 (lane 1), CH101 (lane 2), CH102 (lane 3), CH103 (lane 4), CH104 (lane 5) or $\mathrm{CH} 104 \mathrm{R}$ (lane 6).

(a)

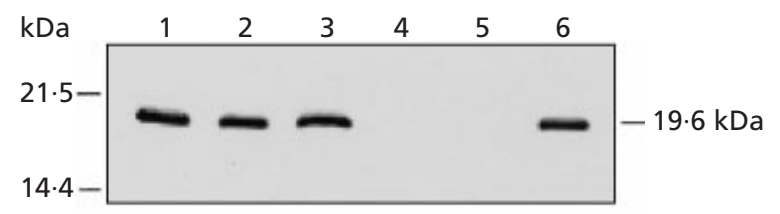

(b)

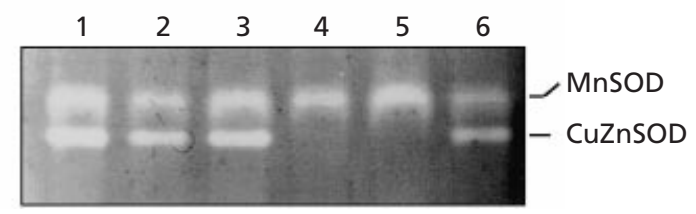

Fig. 2. Verification of the disruption of SOD1 by Western blot analysis (a) and by activity staining (b). SOD activity was revealed by staining the $7.5 \%$ native polyacrylamide gel with nitro blue tetrazolium and riboflavin. A sample $(50 \mu \mathrm{g})$ of the crude extract from exponentially growing cells of CAl4 (lane 1), CH101 (lane 2), CH102 (lane 3), CH103 (lane 4), CH104 (lane 5) or $\mathrm{CH} 104 \mathrm{R}$ (lane 6) was loaded into the wells.

activity staining (Fig. 2b), respectively. To investigate whether wild-type SOD1 could directly restore the phenotypes of a sod1 mutant, one copy of SOD1 was reintroduced into the sod1/sod1 mutant strain (CH104); the correct re-insertion of SOD1 was confirmed by
Southern blot analysis (Fig. 1b), Western blot analysis (Fig. 2a) and activity staining (Fig. 2b).

\section{Determination of growth rate of C. albicans and its morphological phenotype}

When the doubling times $\left(t_{\mathrm{d}}\right)$ of yeast-phase growth of C. albicans were measured in YPG medium at $28{ }^{\circ} \mathrm{C}$, there were no significant differences in the growth rate of the wild-type parental strain (SC5314; $t_{\mathrm{d}}=1 \cdot 12 \pm$ $0 \cdot 01 \mathrm{~h})$ and the growth rate of the homozygous sod $1 /$ sod1 mutant strain $\left(\mathrm{CH} 103 ; t_{\mathrm{d}}=1.19 \pm 0.03 \mathrm{~h}\right)$. Moreover, both strains showed a similar extension rate $(\mu)$ of hyphae in liquid YPG medium supplemented with $10 \%$ serum (SC5314, $\mu=24.4 \pm 0.5 \mu \mathrm{m} \mathrm{h}^{-1} ; \mathrm{CH} 103, \mu=$ $\left.24 \cdot 6 \pm 1 \cdot 6 \mu \mathrm{m} \mathrm{h}^{-1}\right)$.

To examine the effect of the sod1 mutation on the hyphal growth of C. albicans, $\mathrm{Ura}^{+}$prototrophs were grown on several solid or liquid media that induce hyphal growth, e.g. Spider medium (Liu et al., 1994), Lee's medium (Lee et al., 1975), 10\% serum, corn meal agar (Difco) containing 0.33\% Tween 80 and RPMI 1640 medium (Gibco-BRL). Although closer examination of the sod1/sod1 strain revealed no clear differences in the morphological phenotypes of this strain when grown in/on the different media tested, the sod1/sod 1 mutant did show significantly delayed hyphal growth on solid Spider medium. The sod1/sod1 mutant had a wrinkled colony phenotype when grown on Spider medium for 5 days at $37^{\circ} \mathrm{C}$, whereas wild-type and heterozygote cells formed extensive radial filaments when grown on this medium (Fig. 3). When grown on Spider medium the revertant strain (CH104R) regained the capacity to set up hyphal growth, consistent with that of the heterozygote strain grown under the same conditions (Fig. 3).

\section{Effects of oxidants on the sod1/sod 1 mutant}

The defence mechanism of C. albicans against oxidants might be an important factor for survival of this yeast in host phagocytic cells. Thus, we tested whether disruption of SOD1 affected the survival of C. albicans cells in the presence of oxidants. For this purpose, exponentially growing wild-type CAI 4 or sod1/sod $1 \mathrm{CH} 104$ cells were treated with various concentrations of menadione or hydrogen peroxide. After 2 days incubation on YPG medium, the number of viable cells was counted. As shown in Fig. 4(a), disruption of SOD1 made these cells more sensitive to menadione but not to hydrogen peroxide. Similarly, the $\mathrm{Ura}^{+}$sod1/sod1 strain CH103 showed decreased survivability in the presence of menadione (data not shown) and its growth was inhibited in presence of this oxidant when compared to wild-type SC5314 and revertant CH104R cells (Fig. 4b).

\section{Adaptation of the sod1/sod1 mutant to menadione}

An organism pre-treated with a sublethal dose of a particular stress can usually withstand subsequent treatments with higher doses of the same stress. As C. 

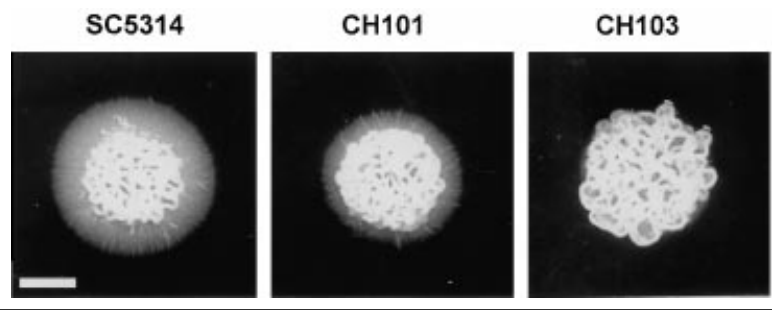

CH104R

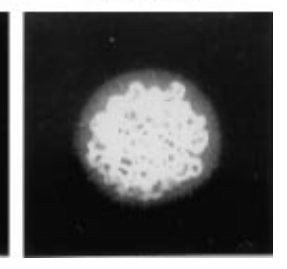

Fig. 3. Defective hyphal growth of the $C$. albicans sod1/sod1 mutant. Each strain was grown on solid Spider medium and photographed after growth for 5 days at $37^{\circ} \mathrm{C}$. Bar, $5 \mathrm{~mm}$ and applies to each panel.
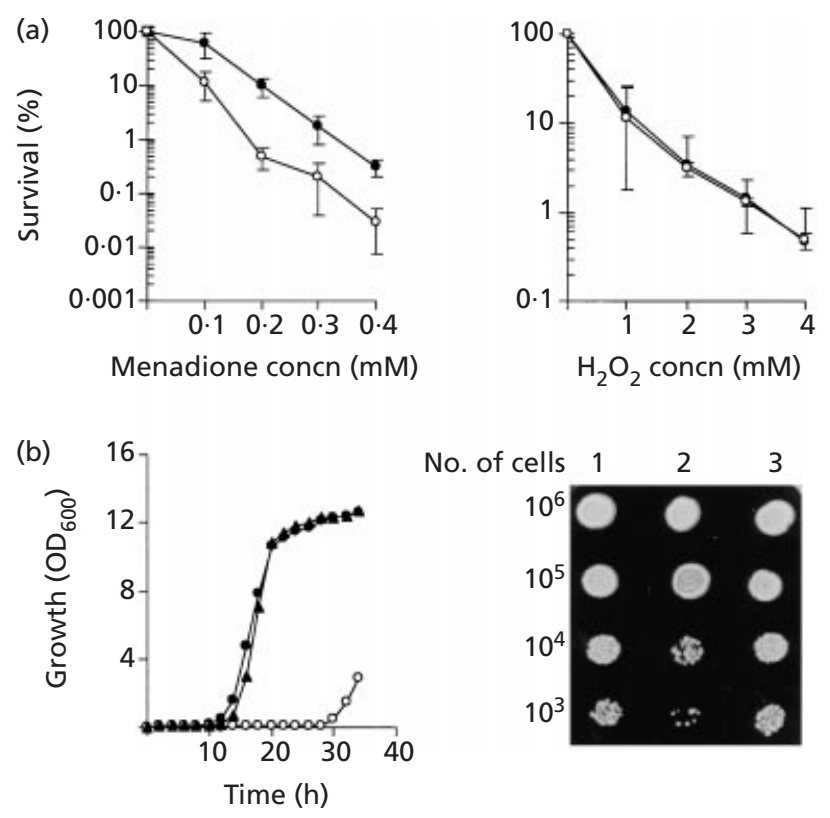

Fig. 4. Effect of oxidants on the $C$. albicans sod $1 /$ sod 1 mutant. (a) Survivabilities of the wild-type CAI4 (O) and sod1/sod1 $\mathrm{CH} 104(\mathrm{O}) \mathrm{Ura}^{-}$strains after treatment with menadione and hydrogen peroxide. The survival of the strains was measured as described in Methods; survival is expressed as a percentage of the number of colonies grown from the treated sample divided by the number of colonies grown from the (untreated) control sample. Data shown represent the mean \pm SE of three independent experiments. (b) Effect of menadione on the growth of C. albicans. Wild-type SC5314 (O), sod1/sod1 CH103 (O) and revertant $\mathrm{CH} 104 \mathrm{R}(\boldsymbol{\Delta}) \mathrm{Ura}^{+}$cells were grown in YPG broth containing $60 \mu \mathrm{g}$ menadione $\mathrm{ml}^{-1}$. Aliquots from the growing cultures were taken at various times and growth was determined as a measure of the $\mathrm{OD}_{600}$ value. For culturing on solid medium, cells of SC5314 (lane 1), CH103 (lane 2) and $\mathrm{CH} 104 \mathrm{R}$ (lane 3) were serially diluted and then spotted onto YPG plates containing $0.3 \mathrm{mM}$ menadione.

albicans can adapt to oxidative stresses and the activity of $\mathrm{Cu} / \mathrm{ZnSOD}$ has been shown to increase significantly (six-fold) upon exposure of the organism to menadione (Jamieson et al., 1996), the role of $\mathrm{Cu} / \mathrm{ZnSOD}$ in the adaptation of $C$. albicans to menadione was tested. Exponentially growing cells of C. albicans were treated with a sublethal concentration of menadione $(25 \mu \mathrm{M})$ for $1 \mathrm{~h}$ in YPG medium. As with cells of the wild-type strain CAI4, cells of the sod1/sod1 mutant CH104 showed an adaptive response when treated with $25 \mu \mathrm{M}$

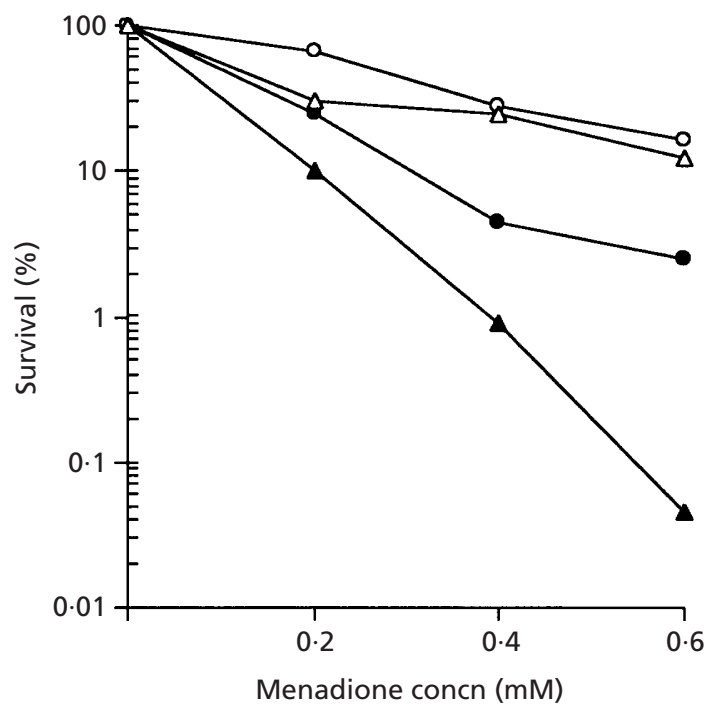

Fig. 5. Effect of SOD1 disruption on the adaptation of $C$. albicans cells to menadione. Cells of $C$. albicans growing exponentially in YPG medium were treated with $0,0.2,0.4$ and $0.6 \mathrm{mM}$ menadione. To induce a sufficient adaptive response, the cells were pre-treated with $25 \mu \mathrm{M}$ menadione for $1 \mathrm{~h}$. CAI4; O, pre-treated CAI4; $\Delta, \mathrm{CH}_{104} ; \triangle$, pre-treated $\mathrm{CH} 104$.

menadione (Fig. 5). Therefore, other anti-oxidant enzymes or factors other than $\mathrm{Cu} / \mathrm{ZnSOD}$ are likely to be involved in the adaptive response of C. albicans to this oxidant.

\section{'Leaky' lysine auxotrophy of the sod1/sod1 mutant}

An E. coli strain with a double MnSOD/FeSOD mutation $(\operatorname{sod} A / \operatorname{sod} B)$ and a Saccharomyces cerevisiae sod1 mutant strain have both been shown to exhibit aerobic auxotrophy when grown on minimal medium, although different factors influenced the auxotrophy observed in these two organisms. For its normal growth, the $S$. cerevisiae sod 1 mutant requires lysine and either cysteine or methionine to be present in the growth medium (Chang et al., 1990; Liu et al., 1992), while the E. coli $\operatorname{sod} A / \operatorname{sod} B$ mutant requires branched amino acids to be present in the growth medium (Fridovich, 1995). To examine whether a sod1 mutation would affect the growth of C. albicans in minimal medium, the doubling times and yields at stationary phase of the wild-type and sod1/sod 1 strains of this organism were 
Table 2. Doubling times and yields of $C$. albicans wild-type, sod $1 /$ sod 1 and revertant cells when grown in minimal medium

Doubling times were determined (as described in Methods) after the $\mathrm{Ura}^{-}$and $\mathrm{Ura}^{+}$cells had been grown at $28{ }^{\circ} \mathrm{C}$ in SG or SGU medium, respectively. Growth yields were measured at $\mathrm{OD}_{600}$ after each strain had been grown to stationary phase in the aforementioned media. Data represent the mean $\pm \mathrm{sE}$ from three independent experiments.

\begin{tabular}{|c|c|c|c|c|c|}
\hline \multirow[t]{3}{*}{ Growth characteristic } & \multicolumn{5}{|c|}{ Strain } \\
\hline & \multicolumn{2}{|c|}{$\mathrm{Ura}^{-}$} & \multicolumn{3}{|c|}{$\mathrm{Ura}^{+}$} \\
\hline & CAI4 & $\mathrm{CH} 104$ & SC5314 & $\mathrm{CH} 103$ & $\mathrm{CH} 104 \mathrm{R}$ \\
\hline Doubling time $(\mathrm{h})$ & $2 \cdot 32 \pm 0 \cdot 15$ & $2 \cdot 76 \pm 0 \cdot 24$ & $2 \cdot 10 \pm 0 \cdot 15$ & $2 \cdot 30 \pm 0 \cdot 08$ & $2 \cdot 27 \pm 0 \cdot 03$ \\
\hline Growth yield $\left(\mathrm{OD}_{600}\right)$ & $6.48 \pm 0.53$ & $4 \cdot 43 \pm 0 \cdot 16$ & $8 \cdot 46 \pm 0 \cdot 47$ & $7 \cdot 10 \pm 0 \cdot 20$ & $7 \cdot 35 \pm 0 \cdot 28$ \\
\hline
\end{tabular}

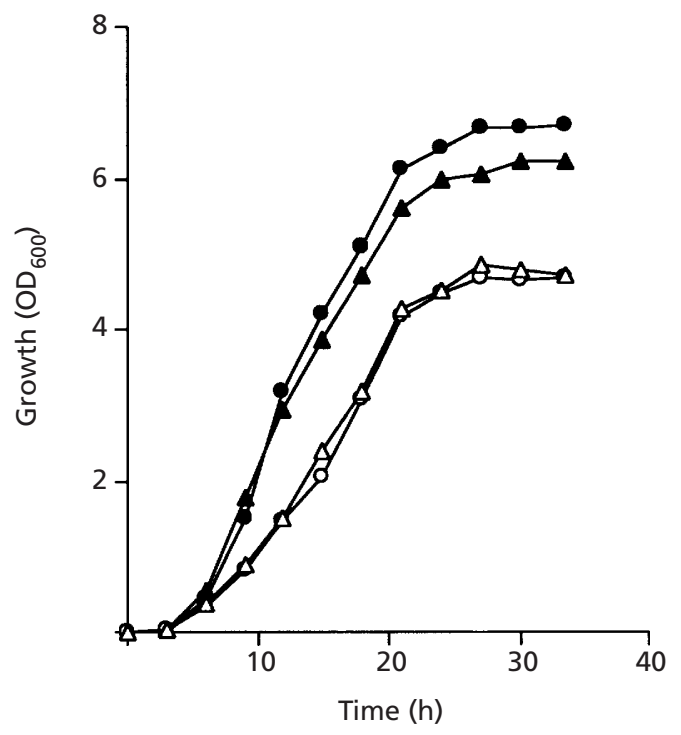

Fig. 6. 'Leaky' lysine auxotrophy of the sod1/sod 1 mutant $\mathrm{CH} 104$. The wild-type CAI4 (O) and sod1/sod1 $\mathrm{CH} 104(\mathrm{O})$ cells were grown aerobically with shaking at 200 r.p.m. in SGU medium at $28{ }^{\circ} \mathrm{C}$. The growth of each strain was determined as a measure of the $\mathrm{OD}_{600}$ value. To examine the amino acid requirements of the sod1/sod1 mutant, sod1/sod 1 cells were also grown in SGU in the presence of $40 \mu \mathrm{g}$ lysine $\mathrm{ml}^{-1}(\boldsymbol{\Delta})$ or $20 \mu \mathrm{g}$ methionine $\mathrm{ml}^{-1}$ plus $20 \mu \mathrm{g}$ cysteine $\mathrm{ml}^{-1}(\triangle)$.

monitored. As shown in Table 2 , the sod $1 / \operatorname{sod} 1$ mutant showed a slower growth rate and lower growth yield when grown in minimal medium compared to the wildtype and revertant cells. However, since the differences (if any) in the growth rates and yields of the different $\mathrm{Ura}^{+}$strains were not that great, we used Ura ${ }^{-}$strains to investigate which amino acids were required for normal growth of the sod1/sod1 mutant. When grown in SGU medium cells of the sod1/sod1 mutant $\mathrm{CH} 104$ grew more slowly than those of wild-type CAI4; however, growth of the sod1/sod 1 mutant was restored by the addition of lysine to the medium, but not by the addition of methionine and cysteine to the medium (Fig. 6).

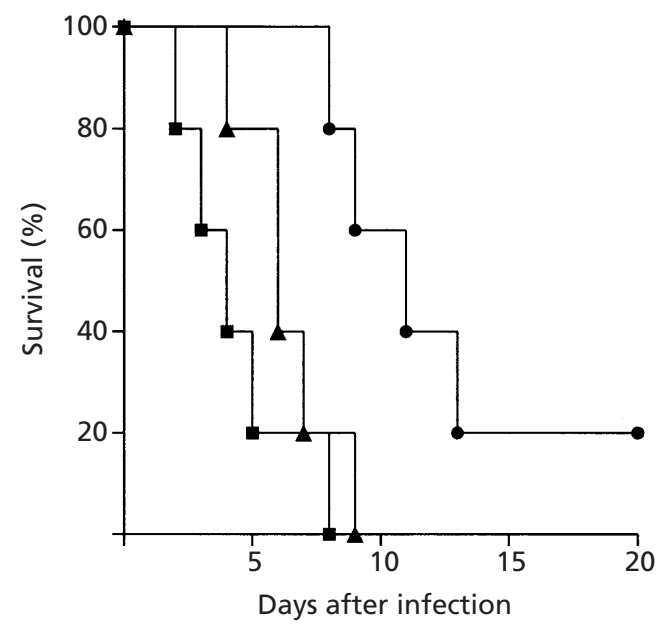

Fig. 7. Virulence assay. $B A L B / c$ mice were inoculated with $1 \times 10^{6}$ cells of SC5314 ( $\left.\mathbf{a}\right), \mathrm{CH} 103(\mathbf{O})$ or $\mathrm{CH} 104 \mathrm{R}(\boldsymbol{\Delta})$ in their tail veins and the survival of the animals was monitored. Curves represent the compiled results of two replicate experiments (five mice per group in each experiment).

Taken together, these results suggested that the $C$. albicans sod1/sod 1 mutant had a 'leaky' lysine auxotrophy.

\section{Survival of the sod1/sod1 mutant in macrophages}

To examine the role of $\mathrm{Cu} / \mathrm{ZnSOD}$ in the defence of $\mathrm{C}$. albicans against the fungicidal mechanism of macrophages, the wild-type (SC5314), sod1/sod1 (CH103) and revertant (CH104R) strains were tested for their abilities to survive in the cell-line RAW264.7, by using the endpoint dilution survival assay (see Methods). When incubated with macrophages, the wild-type, sod1/sod1 and revertant strains survived to $55 \cdot 4 \pm 9 \cdot 6,14 \cdot 2 \pm 6 \cdot 3$ and $39.7 \pm 8.1 \%$, respectively (values based on the number of colonies in the presence of macrophages divided by the number of colonies in the absence of macrophages). This result suggested that the sod $1 / \operatorname{sod} 1$ 
mutant was significantly more susceptible to the fungicidal activity of macrophages than the wild-type and revertant strains.

\section{Virulence study}

To investigate the effect of the sod1 defect on the virulence of C. albicans in a BALB/c mouse model, wildtype, sod1/sod1 and revertant strains of C. albicans were intravenously injected into immunocompetent mice. Since the Ura ${ }^{-}$strains show decreased virulence, only isogenic $\mathrm{Ura}^{+}$strains were used to infect the mice. All of the mice inoculated with the wild-type or revertant cells carrying SOD1 died within 9 days of being inoculated. However, the mice inoculated with the $\mathrm{Cu} / \mathrm{ZnSOD}$-deficient strain survived significantly longer than those inoculated with the wild-type parental or revertant strains in each of two separate experiments (Fig. 7). The survival differences between the sod $1 / \operatorname{sod} 1$ and wild-type or revertant strains were significant $(P<0.05$, according to the Kaplan-Meier log-rank test $)$. This result indicated that $\mathrm{Cu} / \mathrm{ZnSOD}$ contributes to the virulence of C. albicans in a mouse model of intravenous infection.

\section{DISCUSSION}

This study describes the effects of $\mathrm{Cu} / \mathrm{ZnSOD}$ on the morphological phenotype, oxygen metabolism and virulence of C. albicans. To investigate the function of $\mathrm{Cu} / \mathrm{ZnSOD}$ in C. albicans, we sequentially disrupted the gene encoding this enzyme, SOD1 (Fig. 1). The resulting sod1/sod1 mutant showed delayed hyphal growth on Spider medium (Fig. 3), although no clear differences in the morphological phenotypes of this strain were observed when it was grown in/on the other hypha-inducing media tested. Some reports suggest that $\mathrm{Cu} / \mathrm{ZnSOD}$ may play a role in fungal differentiation; for example, sod1 mutants of Neurospora crassa or $S$. cerevisiae showed reduced mycelial growth or defective spore formation, respectively, when compared to the wild-types (Chary et al., 1994; Liu et al., 1992). Additionally, it has been reported that the $\mathrm{Cu} / \mathrm{ZnSOD}$ activity of C. albicans increases during the morphological transition of the organism from yeast-like to hyphal growth (Gunasekaran et al., 1998). Thus, our finding that disruption of SOD1 led to defective hyphal development by the resulting C. albicans mutant strain when grown on Spider medium reinforces the possibility that $\mathrm{Cu} / \mathrm{ZnSOD}$ is likely to be involved in the morphogenesis of C. albicans under some conditions.

C. albicans sod $1 /$ sod 1 cells had similar phenotypes to $S$. cerevisiae sod 1 cells with respect to their sensitivity to increasing concentrations of menadione (Fig. 4), their slow aerobic growth in minimal medium (Table 2) and their 'leaky' lysine auxotrophy (Fig. 6). However, the sod1/sod1 mutant showed no auxotrophy for methionine or cysteine. The requirement of either methionine or cysteine to be present for the growth of $S$. cerevisiae sod1 cells is apparently not a true auxotrophy, but rather results from the metabolic consequences of sulfur assimilation, which increases in the absence of sulfurcontaining amino acids (Chang et al., 1990). Thus, the C. albicans sod1/sod1 cells examined here seem to be more resistant to attack by the superoxide radical anionmediated sulfur radicals formed during sulfur assimilation than $S$. cerevisiae sod1 cells. Recently, it has been reported that C. albicans has an unusual cytoplasmic MnSOD that confers anti-oxidant protection to the organism during its growth phases (Lamarre et al., 2001); this cytoplasmic MnSOD has also been found in a few other organisms, including unicellular green algae (Kitayama \& Togasaki, 1995) and filamentous fungi (Diez et al., 1998). Unlike the situation with the $S$. cerevisiae sod1 strain, the cytosolic MnSOD of C. albicans, possibly, relieves the detrimental effect of a sod1 defect in this organism. Therefore, it is plausible (as one of a number of explanations) that the C.albicans sod1/sod 1 cells have a diminished requirement for the essential amino acids lysine, methionine or cysteine to be present in minimal medium when grown under aerobic conditions compared to that of $S$. cerevisiae sod1 cells. An N. crassa sod1 mutant did not show any auxotrophy when grown aerobically in minimal medium (Chary et al., 1994). Taken together, these results indicate that across fungal species there might be, to varying extents, differences in the abilities of different species to resist toxic products derived from superoxide radical anions.

C. albicans is a member of the normal microflora of humans and does not usually cause disease in immunocompetent hosts. However, C. albicans causes serious diseases in immunocompromised individuals, such as patients suffering from leukaemia or diabetes, those that have undergone recent organ transplant and humanimmunodeficiency-virus-infected individuals (Coleman et al., 1993). For the removal of C. albicans from the infected host, infected host cells require the interaction of many different types of immune cells with several candidacidal mechanisms. Oxygen-dependent killing mechanisms are very important in the removal of $C$. albicans from the infected host; these include the superoxide radical anion, myeloperoxidase hydrogen peroxide/halide system and reactive nitrogen intermediate responses of host macrophages (Vázquez-Torres \& Balish, 1997). Therefore, the anti-oxidant defence systems of C. albicans are assumed to be essential for this organism to resist the host immune response and for it to exhibit its full virulence. In agreement with this view, exogenous anti-oxidants have been shown to impair the killing of C. albicans cells by neutrophils (Wagner $e$ t al., 1986) and a catalase-deficient (Wysong et al., 1998) or erythroascorbic acid-deficient C. albicans strain (Huh et al., 2001) has been shown to be far less virulent for mice than the parental wild-type strain. The present study also shows that the $\mathrm{Cu} / \mathrm{ZnSOD}$-deficient strain used here has an increased susceptibility to fungicidal damage by macrophages and attenuated virulence in a mouse model for systemic candidiasis (Fig. 7). Considering the function of $\mathrm{Cu} / \mathrm{ZnSOD}$ as an anti-oxidant enzyme, our 
results and those of others suggest that $\mathrm{Cu} / \mathrm{ZnSOD}$ may be essential for C. albicans to resist the oxidantmediated killing actions of the host immune system. Another possible explanation for the attenuated virulence of the C. albicans sod $1 / \operatorname{sod} 1$ cells observed here is likely to involve lysine biosynthesis. Since host cells do not possess the ability to synthesize lysine, an essential nutrient, infecting C. albicans cells can only utilize this limited nutrient via a de novo pathway (Broquist, 1971). However, this possibility seems to be very unlikely because the differences, if any, in the doubling times and yields between sod1/sod1 and wild-type or revertant pathogenic $\mathrm{Ura}^{+}$strains were very small when the strains were grown in minimal medium (Table 2). It is also well known that there is a strong correlation between the morphological transition of C. albicans from yeast-like to hyphal growth and its virulence. The positive control of hyphal development in C. albicans is signalled, to a certain extent, via the MAP kinase cascade to activate the transcription factor Cph1, whose deletion results in suppressed hyphal growth of C. albicans on Spider medium (Liu et al., 1994). The cph1/cph1 mutant can develop hyphae when grown in serum or liquid media and is as virulent as the wild-type strain (Lo et al., 1997). Since C. albicans sod 1 /sod 1 cells still form hyphae when grown in liquid culture and in response to serum (like the $c p h 1 / c p h 1$ mutant cells), the delayed hyphal growth of this strain on Spider medium is unlikely to be the major cause of its attenuated virulence.

In conclusion, we have shown that $\mathrm{Cu} / \mathrm{ZnSOD}$ of $C$. albicans plays roles in the protection of this organism from oxidative stresses, in its defective hyphal development on Spider medium, in its survival in macrophages and in the establishment of its full virulence in a mouse infection model. Thus, our findings demonstrate that $\mathrm{Cu} / \mathrm{ZnSOD}$ is involved in the virulence of $C$. albicans and provide important clues as to how the antioxidant enzymes of fungal pathogens function in the infection process.

\section{ACKNOWLEDGEMENTS}

We thank William A. Fonzi for C. albicans CAI4 and plasmid p5921, and also Hyungsoo Kim and Gajin Jeong for their excellent technical help with the mice experiments. This work was supported by a grant from the Korea Health 21 R\&D Project, Ministry of Health \& Welfare, Republic of Korea (00PJ1-PG3-20200-0036) and by a Research Fellowship from the BK21 project.

\section{REFERENCES}

Battistoni, A., Donnarumma, G., Greco, R., Valenti, P. \& Rotilio, G. (1998). Overexpression of a hydrogen peroxide-resistant periplasmic $\mathrm{Cu}, \mathrm{Zn}$ superoxide dismutase protects Escherichia coli from macrophage killing. Biochem Biophys Res Commun 243, 804-807.

Bollag, D. M. \& Edelstein, S. J. (1991). Immunoblotting. In Protein Methods, pp. 181-211. New York: Willey-Liss.

Broquist, H. P. (1971). Lysine biosynthesis (yeast). Methods Enzymol 17, 112-129.
Chang, E. C. \& Kosman, D. J. (1990). $\mathrm{O}_{2}$-dependent methionine auxotrophy in $\mathrm{Cu}, \mathrm{Zn}$ superoxide dismutase-deficient mutants of Saccharomyces cerevisiae. J Bacteriol 172, 1840-1845.

Chary, P., Dillon, D., Schroeder, A. L. \& Natvig, D. O. (1994). Superoxide dismutase (sod-1) null mutants of Neurospora crassa: oxidative stress sensitivity, spontaneous mutation rate and response to mutagens. Genetics 137, 723-730.

Coleman, D. C., Bennett, D. E., Sullivan, D. J., Gallagher, P. J., Henman, M. C., Stanley, M. B. \& Russell, R. J. (1993). Oral Candida in HIV infection and AIDS: new perspectives/new approaches. Crit Rev Microbiol 19, 61-82.

Culotta, V. C., Joh, H. D., Lin, S. J., Slekar, K. H. \& Strain, J. (1995). A physiological role for Saccharomyces cerevisiae copper/zinc superoxide dismutase in copper buffering. J Biol Chem 270, 29991-29997.

Cutler, J. E. (1991). Putative virulence factors of Candida albicans. Anпu Rev Microbiol 45, 187-218.

Diez, B., Schleissner, C., Moreno, M. A., Rodriguez, M., Collados, A. \& Barredo, J. L. (1998). The manganese superoxide dismutase from the penicillin producer Penicillium chrysogenum. Curr Genet 33, 387-394.

Farrant, J. L, Sansone, A., Canvin, J. R., Pallen, M. J., Langford, P. R., Wallis, T. S., Dougan, G. \& Kroll, J. S. (1997). Bacterial copper- and zinc-cofactored superoxide dismutase contributes to the pathogenesis of systemic salmonellosis. Mol Microbiol 25, 785-796.

Fonzi, W. A. \& Irwin, M. Y. (1993). Isogenic strain construction and gene mapping in Candida albicans. Genetics 134, 717-728.

Fridovich, I. (1989). Superoxide dismutases. An adaptation to a paramagnetic gas. J Biol Chem 264, 7761-7764.

Fridovich, I. (1995). Superoxide radical and superoxide dismutases. Annu Rev Biochem 64, 97-112.

Gunasekaran, U., Yang, R. \& Gunasekaran, M. (1998). Regulation of superoxide dismutase synthesis in Candida albicans. Mycopathologia 141, 59-63.

Hamilton, A. J. \& Holdom, M. D. (1999). Antioxidant systems in the pathogenic fungi of man and their role in virulence. Med Mycol 37, 375-389.

Hong, Z., LoVerde, P. T., Hammarskjöld, M. L. \& Rekosh, D. (1992). Schistosoma mansoni: cloning of a complementary DNA encoding cytosolic $\mathrm{Cu} / \mathrm{Zn}$ superoxide dismutase and high-yield expression of the enzymatically active gene product in Escherichia coli. Exp Parasitol 75, 308-322.

Huh, W.-K., Kim, S.-T., Kim, H., Jeong, G. \& Kang, S.-O. (2001). Deficiency of D-erythroascorbic acid attenuates hyphal growth and virulence of Candida albicans. Infect Immun 69, 3939-3946.

Hwang, C.-S., Rhie, G.-e., Kim, S.-T., Kim, Y.-R., Huh, W.-K., Baek, Y.-U. \& Kang, S.-O. (1999). Copper- and zinc-containing superoxide dismutase and its gene from Candida albicans. Biochim Biophys Acta 1427, 245-255.

Izawa, S., Inoue, Y. \& Kimura, A. (1995). Oxidative stress response in yeast: effect of glutathione on adaptation to hydrogen peroxide stress in Saccharomyces cerevisiae. FEBS Lett 368, 73-76.

Jamieson, D. J., Stephen, D. W. S. \& Terriere, E. C. (1996). Analysis of the adaptive oxidative stress response of Candida albicans. FEMS Microbiol Lett 138, 83-88.

Kitayama, M. \& Togasaki, R. K. (1995). Purification and cDNA isolation of chloroplastic phosphoglycerate kinase from Chlamydomonas reinhardtii. Plant Physiol 107, 393-400.

Lamarre, C., LeMay, J. D., Deslauriers, N. \& Bourbonnais, Y. (2001). Candida albicans expresses an unusual cytoplasmic 
manganese-containing superoxide dismutase (SOD3 gene product) upon the entry and during the stationary phase. J Biol Chem 276, 43784-43791.

Lee, K. L., Buckley, H. R. \& Campbell, C. C. (1975). An amino acid liquid synthetic medium for the development of mycelial and yeast forms of Candida albicans. Sabouraudia 13, 148-153.

Liu, H., Köhler, J. \& Fink, G. R. (1994). Suppression of hyphal formation in Candida albicans by mutation of a STE12 homolog. Science 266, 1723-1725.

Liu, X. F., Elashvili, I., Gralla, E. B., Valentine, J. S., Lapinskas, P. \& Culotta, V. C. (1992). Yeast lacking superoxide dismutase. Isolation of genetic suppressors. J Biol Chem 267, 18298-18302.

Lo, H. J., Köhler, J. R., DiDomenico, B., Loebenberg, D., Cacciapuoti, A. \& Fink, G. R. (1997). Nonfilamentous C. albicans mutants are avirulent. Cell 90, 939-949.

Manchenko, G. P. (1994). Superoxide dismutase. In Handbook of Detection of Enzymes on Electrophoretic Gels, p. 98. Boca Raton, FL: CRC.

Okado-Matsumoto, A. \& Fridovich, I. (2001). Subcellular distribution of superoxide dismutases (SOD) in rat liver: $\mathrm{Cu}, \mathrm{Zn}$ SOD in mitochondria. J Biol Chem 276, 38388-38393.

Rhie, G.-e., Hwang, C.-S., Brady, M. J. \& 7 other authors (1999). Manganese-containing superoxide dismutase and its gene from Candida albicans. Biochim Biophys Acta 1426, 409-419.

Rocha, C. R., Schroppel, K., Harcus, D., Marcil, A., Dignard, D., Taylor, B. N., Thomas, D. Y., Whiteway, M. \& Leberer, E. (2001). Signaling through adenylyl cyclase is essential for hyphal growth and virulence in the pathogenic fungus Candida albicans. Mol Biol Cell 12, 3631-3643.

Sambrook, J., Fritsch, E. F. \& Maniatis, T. (1989). Molecular Cloning: a Laboratory Manual, 2nd edn. Cold Spring Harbor, NY : Cold Spring Harbor Laboratory.

Vázquez-Torres, A. \& Balish, E. (1997). Macrophages in resistance to candidiasis. Microbiol Mol Biol Rev 61, 170-192.

Wagner, D. K., Collins-Lech, C. \& Sohnle, P. G. (1986). Inhibition of neutrophil killing of Candida albicans pseudohyphae by substances which quench hypochlorous acid and chloramines. Infect Immun 51, 731-735.

Wilks, K. E., Dunn, K. L. R., Farrant, J. L., Reddin, K. M., Gorringe, A. R., Langford, P. R. \& Kroll, J. S. (1998). Periplasmic superoxide dismutase in meningococcal pathogenicity. Infect Immun 66, 213-217.

Wysong, D. R., Christin, L., Sugar, A. M., Robbins, P. W. \& Diamond, R. D. (1998). Cloning and sequencing of a Candida albicans catalase gene and effects of disruption of this gene. Infect Immun 66, 1953-1961.

Youn, H.-D., Kim, E.-J., Roe, J.-H., Hah, Y. C. \& Kang, S.-O. (1996a). A novel nickel-containing superoxide dismutase from Streptomyces spp. Biochem J 318, 889-896.

Youn, H.-D., Youn, H., Lee, J.-W., Yim, Y.-I., Lee, J.-K., Hah, Y. C. \& Kang, S.-O. (1996b). Unique isozymes of superoxide dismutase in Streptomyces griseus. Arch Biochem Biophys 334, 341-348.

Received 26 March 2002; revised 22 May 2002; accepted 18 July 2002. 